\title{
Uso de 2-octil-cianoacrilato na reconstrução da cavidade anof tálmica de coelhos
}

\author{
2-octyl-cyanoacrylate in rabbitanophthalmic cavity reconstruction
}

\author{
Lucieni Cristina Barbarini Ferraz ${ }^{1}$ \\ Silvana Artioli Schellini ${ }^{2}$ \\ Sheila Lordelo Wludarski ${ }^{3}$ \\ Carlos Roberto Padovani ${ }^{4}$ \\ Sérg’io Müller ${ }^{5}$
}

\section{RESUMO}

Objetivo: Avaliar a ligação entre músculos oculares extrínsecos e esferas de polietileno poroso usando um bioadesivo. Métodos: Estudo experimental envolvendo 8 coelhos albinos submetidos a enucleação do olho direto com colocação de implante esférico de polietileno poroso de $12 \mathrm{~mm}$ de diâmetro unido aos músculos oculares extrínsecos por meio do bioadesivo 2-octil-cianoacrilato. Noventa dias após a cirurgia os animais foram sacrificados e o conteúdo orbitário removido. Em 4 animais foi realizado estudo biomecânico, avaliando-se a força de ruptura entre a musculatura e a esfera (grupo implante) e entre a musculatura e a esclera nos olhos contralaterais (grupo controle). Nos outros 4 animais foi realizada análise histológica. Resultado: A avaliação biomecânica revelou que a força de ruptura entre esfera-músculo e esclera-músculo foram semelhantes quando se usa o adesivo de cianoacrilato. O exame histológico mostrou reação fibrovascular no local da adesão entre a musculatura e a esfera, sem efeitos deletérios aos tecidos. Ao redor dos implantes foi possível observar pseudocápsula e no interior, neovasos e tecido fibrovascular preenchendo os espaços entre os grânulos do polietileno. Conclusão: $\mathrm{O}$ adesivo 2-octil-cianoacrilato mantém boa força de adesão na união entre os músculos e as esferas de polietileno poroso, com redução do tempo cirúrgico e sem efeitos deletérios aos tecidos orbitais. Desta forma, deve-se considerar o uso do bioadesivo na reconstrução da cavidade anoftálmica.

apresentada ao Curso de Bases Gerais da Cirurgia - UNESP - e orientada pela Dra. Silvana Artioli Schellini, tendo recebido financiamento da CAPES para sua execução.

${ }^{1}$ Pós-Graduanda do Departamento de Oftalmologia, Otorrinolaringologia e Cirurgia de Cabeça e Pescoço da Faculdade de Medicina da Universidade Estadual Paulista "Júlio Mesquita Filho" - UNESP - Botucatu (SP) Brasil.

${ }^{2}$ Livre Docente do Departamento de Oftalmologia, Otorrinolaringologia e Cirurgia de Cabeça e Pescoço da Faculdade de Medicina da UNESP - Botucatu (SP) Brasil.

${ }^{3}$ Médica Patologista - Consultoria em Patologia - Botucatu (SP) - Brasil.

${ }^{4}$ Professor Titular do Departamento de Bioestatística, Instituto de Biociências da Faculdade de Medicina da UNESP - Botucatu (SP) - Brasil.

${ }^{5}$ Professor do Departamento de Cirurgia da Faculdade de Medicina da UNESP - Botucatu (SP) - Brasil.

Endereço para correspondência: Silvana Artioli Schellini. DEP. OFT/ORL/CCP - Faculdade de Medicina de Botucatu - UNESP - Botucatu (SP) CEP 18618-970 E-mail: sartioli@fmb.unesp.br

Recebido para publicação em 28.06.2005

Última versão recebida em 26.10.2006

Aprovação em 27.11.2006

Nota Editorial: Depois de concluída a análise do artigo sob sigilo editorial e com a anuência dos Drs. Joelice dos Santos Araújo e Sérgio Burnier sobre a divulgação de seu nome como revisor, agradecemos sua participação neste processo.
Descritores: Músculos oculomotores/efeitos de drogas; Cianoacrilatos; Polietileno; Adesivos/uso terapêutico; Biomecânica; Coelhos/cirurgia; Histologia

\section{INTRODUÇÃO}

Para que exista melhor mobilidade dos implantes (ou esferas) aloplásticos, nos portadores de cavidades anoftálmicas, os músculos oculares extrínsecos devem ser suturados diretamente aos implantes ou ao seu envoltório.

O uso de adesivos cirúrgicos para fixar a esfera nos músculos oculares extrínsecos está sendo sugerido como alternativa ao fio de sutura nas cirurgias palpebrais e estrabismo ${ }^{(1)}$ e também na fixação da esfera aloplástica nas cavidades anoftálmicas, principalmente por possibilitar menor tempo cirúrgico $^{(2)}$.

Além do aspecto da toxicidade e estética, quando se utiliza o adesivo biológico, também é importante observar se existe resistência adequada à tração e estudos desta natureza ainda não foram realizados.

O objetivo deste estudo é avaliar o uso de adesivo biológico para unir a musculatura ocular extrínseca à esfera de polietileno poroso nas cavidades enucleadas de coelhos. 


\section{MÉTODOS}

Este estudo recebeu a aprovação da Comissão de Ética em Experimentação Animal, da Universidade Estadual Paulista (UNESP) - Faculdade de Medicina de Botucatu para a sua realização.

Foram utilizados 8 coelhos, submetidos a enucleação do olho direito e implante de esferas de polietileno poroso (HOMUS Biotecnologia - São Paulo, Brasil) de $12 \mathrm{~mm}$ de diâmetro. O músculo reto superior e inferior foram atados à esfera usando um bioadesivo (2-octil-cianoacrilato), aplicado sob a musculatura e pressionado contra a esfera, por 5 segundos (Figura 1).

Após a cirurgia, os animais tiveram água e ração ad libitum e foram clinicamente observados por 90 dias e após, sacrificados.

Quatro coelhos tiveram ambos conteúdos orbitais removidos e realizado estudo biomecânico, avaliando-se a força de ruptura entre o músculo e a esfera (grupo implante) comparando-a com a força entre o músculo e a esclera (grupo controle). A variável avaliada pelo teste biomecânico foi a força de ruptura dos músculos reto superior e inferior, usando a Máquina Universal de Ensaios Mecânicos - EIMC9, modelo DL 10.000. Para acondicionamento dos bulbos oculares ou das esferas atadas à musculatura, foi construído um continente (Figura 2). As medições obtidas pelo teste biomecânico foram avaliadas pelo Teste T para amostras dependentes, com nível de significância de $5 \%{ }^{(3)}$.

O conteúdo orbital dos outros 4 coelhos foi preparado para avaliação histológica pela técnica de hematoxilina-eosina, e o exame foi feito com ênfase na integração entre a musculatura, bioadesivo e esfera.

\section{RESULTADOS}

Até o final do experimento os animais não apresentaram sinais de infecção, deiscência ou extrusão dos implantes.

A utilização da cola para unir esfera e musculatura mostrou- se um procedimento rápido e eficiente, tendo-se observado que 5 segundos foram suficientes para que houvesse boa adesão.

Teste biomecânico: os valores em ambos os grupos foram semelhantes, não havendo diferença estatística entre os músculos atados com o bioadesivo à esfera, grupo implante, e o grupo controle (Tabela 1).

Avaliação histológica: no interior das esferas de polietileno foi possível observar reação fibrovascular e poucas células inflamatórias preenchendo os poros da esfera. Ao redor dos implantes observou-se uma estreita pseudocápsula. A reação fibrovascular foi mais densa nas regiões próximas da musculatura ocular extrínseca e da esfera. Porém, não foram observados sinais de alterações teciduais que fossem causados pelo uso da cola ou mesmo a própria cola de 2-octil-cianoacrilato (Figuras 3 e 4 ).

\section{DISCUSSÃO}

A aplicação do 2-octil-cianoacrilato para unir a musculatura ocular extrínseca às esferas nas cavidades anoftálmicas dos coelhos é um procedimento fácil, rápido e seguro. Embora este procedimento já tenha sido descrito anteriormente ${ }^{(2)}$, a sua aplicação clínica continua inexistente.

Os músculos oculares extrínsecos selecionados para a fixação aos implantes foram os músculos retos superior e inferior, por serem mais facilmente identificados, reparados e fixados que os oblíquos. Assim, usando esses músculos o teste biomecânico se torna mais preciso. Outros autores também fixaram estes mesmos músculos, deixando os oblíquos soltos na cavidade orbital ${ }^{(4)}$, havendo ainda referências de fixação também destes músculos ${ }^{(2,5)}$.

Avaliações anteriores sobre a cola de cianoacrilato em musculatura ocular extrínseca foram feitas após 45 ou 60 dias da cirurgia ${ }^{(1-2)}$. O presente estudo testou a adesão após 90 dias e a esfera continuava fortemente aderida à musculatura.

Foram sugeridos 15 segundos para que o bioadesivo 2octil-cianoacrilato conseguisse aderir com a musculatura ocu-

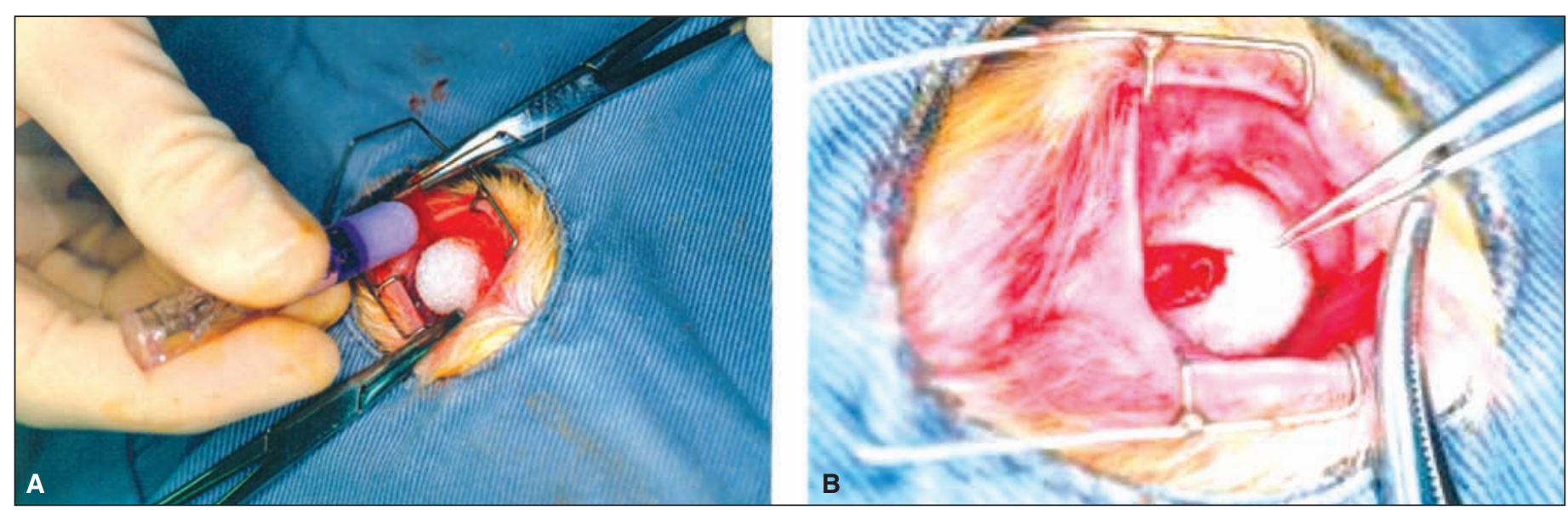

Figura 1 - Aplicação da cola de cianoacrilato entre a musculatura ocular extrínseca de coelho e esfera de polietileno poroso (A) e aspecto final (B) 
lar extrínseca ${ }^{(2)}$. Entretanto, 5 segundos foram suficientes. Desta forma constata-se que o procedimento além de eficiente é muito rápido, podendo reduzir o tempo operatório.

No presente estudo, o teste de força de ruptura mostrou resultados semelhantes entre os músculos normais e os atados com cola. Este fato foi também relatado por outros autores ${ }^{(2)}$.

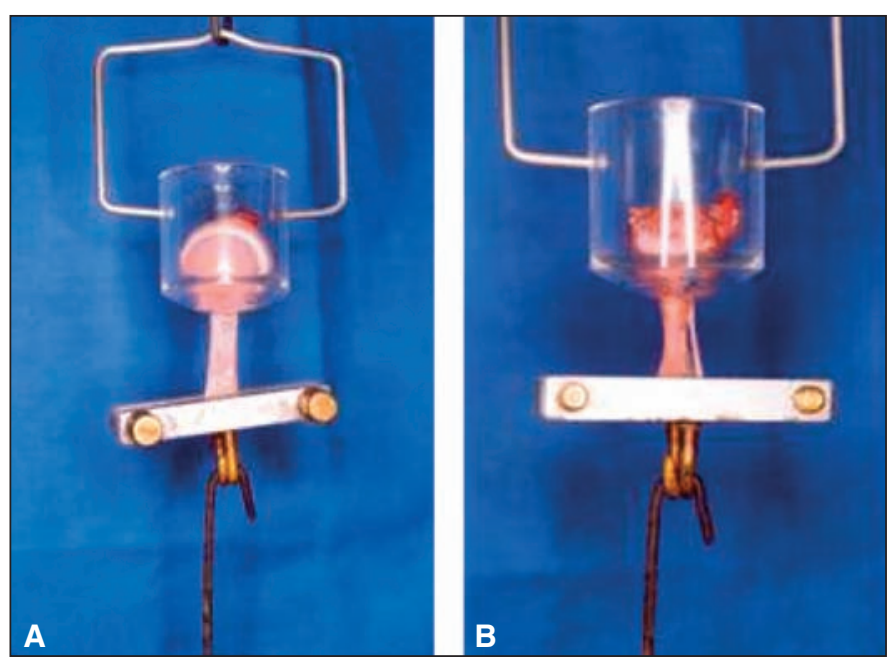

Figura 2 - Ensaio biomecânico. Observar o continente idealizado para a avaliação da força de ruptura dos músculos oculares extrínsecos, contendo o olho (A) e a esfera (B).

\begin{tabular}{|c|c|c|c|}
\hline Músculo & $\begin{array}{l}\text { Grupo } \\
\text { implante }\end{array}$ & $\begin{array}{c}\text { Grupo } \\
\text { normal }\end{array}$ & $\begin{array}{l}\text { Resultado do } \\
\text { teste estatístico }\end{array}$ \\
\hline RS & $437,50 \pm 69,86$ & $523,58 \pm 078,44$ & $2,08(p=0,129)$ \\
\hline RI & $404,18 \pm 75,65$ & $642,20 \pm 110,73$ & $2,75(p=0,071)$ \\
\hline \multicolumn{4}{|c|}{$\mathrm{RS}=$ reto superior; $\mathrm{Rl}=$ reto inferior } \\
\hline
\end{tabular}

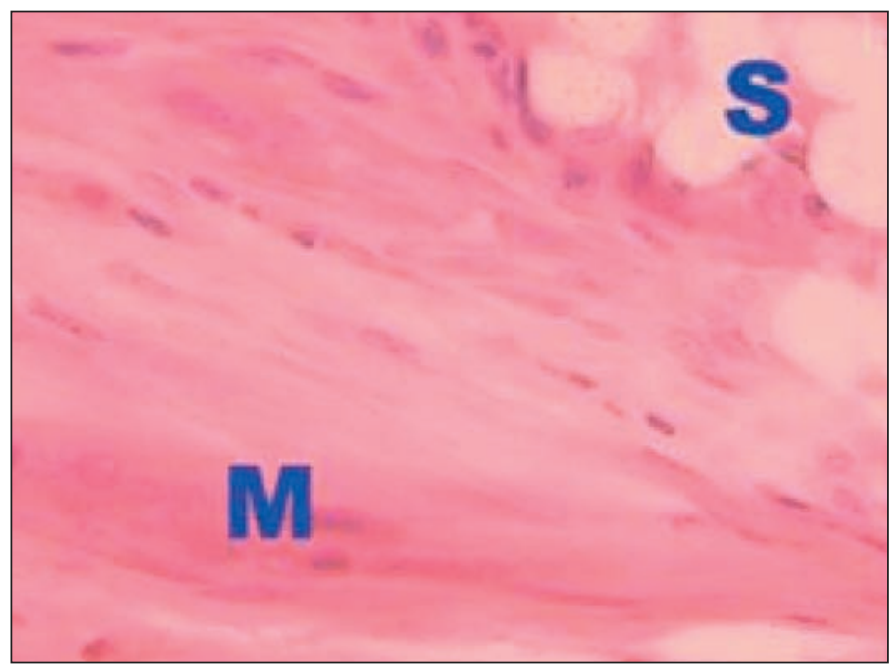

Figura 3 - Integração esfera - hospedeiro. Observar que o músculo (M) está junto à esfera (S) e não existem sinais da cola entre eles (HEX100)
A reação tecidual entre o hospedeiro e a esfera de polietileno poroso já é conhecida, apresentando fibroblastos, algumas células inflamatórias e proliferação de neovasos preenchendo os poros dos implantes ${ }^{(6)}$. Usando o bioadesivo, os neovasos foram mais abundantes principalmente próximos à musculatura ocular extrínseca ${ }^{(7-8)}$, o que pode ser reflexo da presença das artérias musculares que trariam para a área de cicatrização maior afluxo de células inflamatórias e fibrina, facilitando o processo de reparação tecidual.

A avaliação histológica foi importante para mostrar que a musculatura ocular extrínseca estava próxima da esfera, na posição desejada e aderida ao implante por meio de proliferação de tecido fibrovascular. A cola não foi encontrada no local da aplicação, supondo-se que possa ter ocorrido fagocitose ou absorção daquele material. Nenhum efeito deletério aos tecidos ocorreu próximo do local de aplicação, sinal que o cianocrilato é inerte e não provoca danos aos tecidos que o recebem.

\section{CONCLUSÃO}

O adesivo 2-octil-cianoacrilato mantém boa força de adesão entre os músculos e as esferas de polietileno poroso, com redução do tempo cirúrgico e sem efeitos deletérios aos tecidos orbitais. Desta forma, sugere-se o uso do bioadesivo na reconstrução da cavidade anoftálmica.

\section{ABSTRACT}

Purpose: To evaluate fixation by a bioadhesive of the external ocular muscles to the porous polyethylene spheres. Methods: An experimental study was performed using eight white rabbits that underwent right eye enucleation with placement of $12 \mathrm{~mm}$ spheres of porous polyethylene. The rectus muscles (superior and inferior) were attached to the implant with a

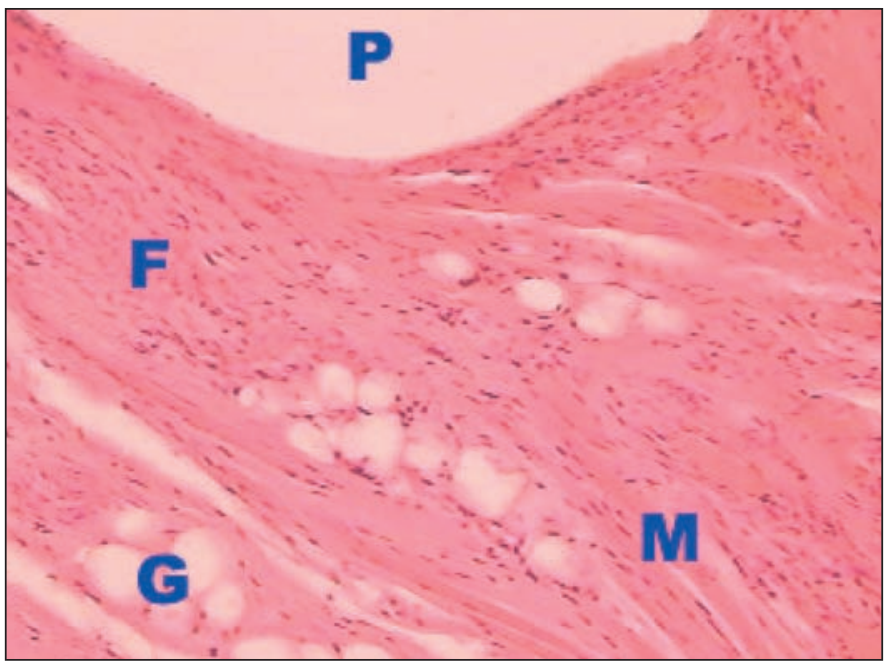

Figura 4 - Integração esfera - hospedeiro. A musculatura (M) está justaposta a esfera. Fibrose (F), gordura (G) e implante (P). (HEX40). 
bioadhesive (2-octyl-cyanoacrylate) applied to the inferior side of the external muscles. Ninety days after surgery the orbital content was removed and 4 animals were submitted to a tensile strength test of the muscle-sphere attachment and the other 4 to histological evaluation. Results: The tensile strength test showed that the rupture force was similar between the muscle and porous polyethylene sphere bond attachment and normal external ocular muscles. The histologic evaluation showed fibrous tissue reaction and muscle-sphere attachment with no deleterious effects to the tissues; a capsule formation around the spheres and new vessels inside the implant were also observed. Conclusion: 2-octyl-cyanoacrylate provides strength adhesion between muscles and spheres, with surgery time reduction and does not provoke deleterious effects on the orbital tissues. Thus, the bioadhesive might be a good choice for use in the anophthalmic cavity reconstruction.

Keywords: Oculomotor muscles/drug effects; Cyanoacrylates; Polyethylenes; Adhesives/therapeutic use; Biomechanics; Rabbits/surgery; Histology

\section{REFERÊNCIAS}

1. Ricci B, Ricci F, Bianchi PE. Octyl 2-cyanoacrylate in sutureless surgery of extraocular muscles: an experimental study in the rabbit model. Graefes Arch Clin Exp Ophthalmol. 2000;238(5):454-8.

2. Gupta BK, Edward D, Duffy MT. 2-Octyl cyanoacrylate tissue adhesive and muscle attachment to porous anophthalmic orbital implants. Ophthal Plast Reconstr Surg. 2001;17(4):264-9.

3. Norman GR, Streiner DL. Biostatistics: the bare essentials. St. Louis: Mosby; c1994.

4. Soll DB, Soll SM, Asbell RL. Evolution and current concepts in the treatment of the anophthalmic socket. In: Nesi FA, Lisman RD, Levine MR, editors. Smith's ophthalmic plastic and reconstructive surgery. St. Louis: Mosby-Year Book; 1998. p.1064-78.

5. Schaefer DP, Rocca CD. Enucleation. In: Nesi FA, Lisman RD, Levine MR, editors. Smith's ophthalmic plastic and reconstructive Surgery. St. Louis: Mosby-Year Book; 1998. p.1015-52.

6. Schellini SA, Marques ME, Padovani CR, Taga EM, Rossa R. Comparison of synthetic hydroxyapatite and porous polyethylene implants in eviscerated rabbit eyes. Ophthal Plast Reconstr Surg. 2003;19(2):136-9.

7. Rubin PA, Popham JK, Bilyk JR, Shore JW. Comparison of fibrovascular ingrowth into hydroxyapatite and porous polyethylene orbital implants. Ophthal Plast Reconstr Surg. 1994;10(2):96-103.

8. Soparkar CN, Wong JF, Patrinely JR, Davidson JK, Appling D. Porous polyethylene implant fibrovascularization rate is affected by tissue wrapping, agarose coating, and insertion site. Ophthal Plast Reconstr Surg. 2000;16(5):330-6.

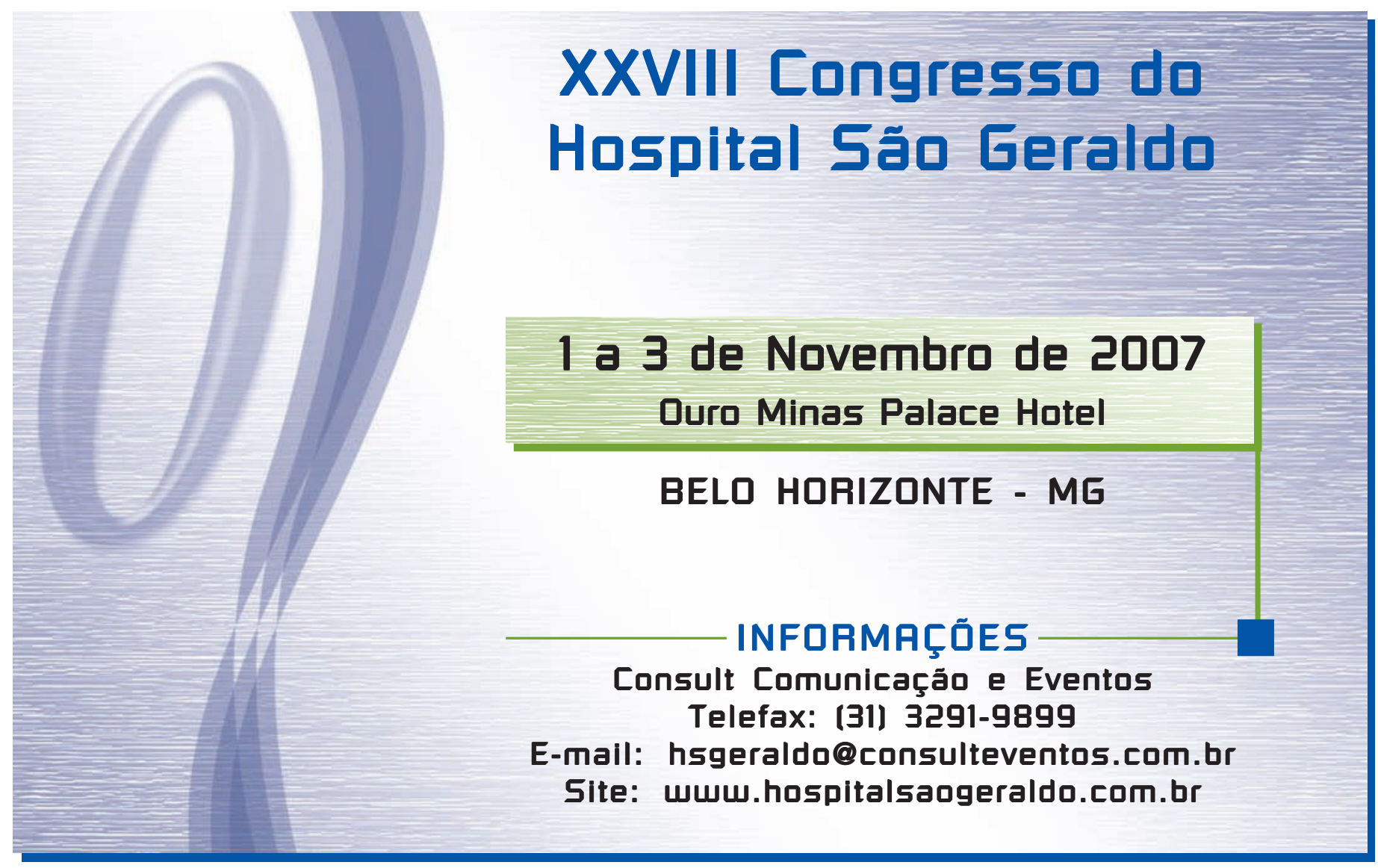

